\title{
Application of the Maximum Entropy Production Model of Evapotranspiration over Partially Vegetated Water-Limited Land Surfaces
}

\author{
ISLEM HAJJI AND DANIEL F. NADEAU \\ Department of Civil and Water Engineering, Université Laval, Quebec, Quebec, Canada \\ BILJANA MUSIC \\ Ouranos-Consortium on Regional Climatology and Adaptation to Climate Change, Montreal, and \\ Department of Civil and Water Engineering, Université Laval, Quebec, Quebec, Canada \\ FRANÇOIS ANCTIL \\ Department of Civil and Water Engineering, Université Laval, Quebec, Quebec, Canada \\ JINGFENG WANG \\ Georgia Institute of Technology, Atlanta, Georgia
}

(Manuscript received 17 July 2017, in final form 26 March 2018)

\begin{abstract}
The maximum entropy production (MEP) model based on nonequilibrium thermodynamics and the theory of Bayesian probabilities was recently developed to model land surface fluxes, including soil evaporation and vegetation transpiration. This model requires few input data and ensures the closure of the surface energy balance. This study aims to test the capability of such a model to realistically simulate evapotranspiration (ET) over a wide range of climates and vegetation covers. A weighting coefficient is introduced to calculate total ET from soil evaporation and vegetation transpiration over partially vegetated land surfaces, resulting in the MEP-ET model. Using this coefficient, the model outputs are compared with in situ observations of ET at eight FLUXNET sites across the continental United States. Results confirm the close agreement between the MEP-ET predicted daily ET and the corresponding observations at sites characterized by moderately limited water availability. Poor ET results were obtained under high water stress conditions. A regulation parameter was therefore introduced in the MEP-ET model to properly take into account the effects of soil water stress on stomata, yielding the generalized MEP-ET model. This parameter considerably reduced model biases under water stress conditions for various heterogeneous land surface sites. The generalized MEP-ET model outperforms several popular ET models, including Penman-Monteith (PM), modified Priestley-Taylor-Jet Propulsion Laboratory (PT-JPL), and air-relative-humidity-based two-source model (ARTS) at all test sites.
\end{abstract}

\section{Introduction}

Evapotranspiration (ET) linking water and energy budgets is one of the most challenging hydrometeorological processes to monitor and model due to the complex interactions among the components of the soilplant-atmosphere system (Zhao et al. 2013). Various methods, such as empirical relationships (Kohler et al. 1955), energy budget (Fritschen 1966; Kustas and Norman 1996; Ershadi et al. 2014), bulk transfer (Harbeck 1962; Isabelle et al. 2015), combined energy

Corresponding author: Islem Hajji, islem.hajji.1@ulaval.ca budget-bulk transfer methods (Penman 1948; Duan and Bastiaanssen 2017), and eddy covariance systems (Baldocchi et al. 1988; Aubinet et al. 2012), have been used to quantify ET. The latter is certainly the most direct approach, but requires intensive technical supervision to effectively implement and operate (Shi et al. 2008).

Recent advances in contemporary nonequilibrium thermodynamics, building on the Bayesian probability and information theories, have provided a new theoretical basis for modeling ET. In this context, it was recently shown that the maximum entropy production (MEP) method may be an effective new approach for modeling ET (Wang and Bras 2009, 2011). The MEP theory is 
originated from the treatise of statistical mechanics pioneered by Gibbs (1902) for an ensemble of thermodynamic systems. Jaynes (1957) was the first to realize that Gibbs's algorithm, now known as the maximum entropy (MaxEnt) principle, is a general inference algorithm based on incomplete information quantified by Shannon entropy (Shannon 1948). The reader is referred to the work of Jaynes (2003) for a comprehensive account of the MaxEnt theory. The MEP theory has received increasing attention in recent years (Ozawa et al. 2003; Kleidon and Lorenz 2004; Martyushev and Seleznev 2006; Kleidon 2009). Wang and Bras (2011) have applied the MEP theory to develop a new model of evapotranspiration and surface heat fluxes using a framework conceptually different from standard "physically based" approaches. It was formulated by combining physical principles such as conservation of energy and boundary layer turbulence, among others, with probability rules. It differs from conventional bulk transfer models in several fundamental aspects by 1) predicting surface fluxes without using temperature and humidity gradients, wind speed, and surface roughness as input variables; 2) always closing the surface energy budget, given that the energy balance equation is used as a mathematical constraint of the MEP solution of the surface fluxes; and 3) solving the surface fluxes using only net radiation, surface temperature, and surface specific humidity. Although the surface fluxes are calculated from three input variables (temperature, humidity, and net radiation), it is important to emphasize that the effects of other atmospheric and land surface conditions are taken into account through the model parameters (i.e., thermal inertia). Even with fewer input variables compared to other physically based ET models, the MEP model includes all essential physical processes behind ET under more general conditions (Wang et al. 2012). The MEP model is thus devised to make an effective use of a small number of input variables to calculate the surface fluxes.

Two different versions of the MEP model can be distinguished: MEP-Ev for soil evaporation and MEP-Tr for plant transpiration. Both have already been used successfully to estimate subdaily evaporation over bare soil (MEP-Ev) and transpiration over dense vegetation (MEP-Tr) under humid to moderately limited water availability conditions (Wang and Bras 2011). More recent studies (Shanafield et al. 2015; Wang et al. 2017) have also tested the MEP-Tr model at a humid forest site and the MEP-Ev model at an arid, nonvegetated site with encouraging results. However, further tests of the MEP model are needed to investigate its capability to estimate the seasonal variation of ET under the conditions of severe water stress and in the presence of a partially vegetated cover.
The first objective of the present study is to formulate a combined MEP model, hereafter referred to as MEP-ET, using a vegetation weighting coefficient $f_{\text {veg }}$ to combine the MEP-Ev and MEP-Tr estimates for partially vegetated land surfaces. The second objective is to evaluate the performance of the MEP-ET model at eight sites from different biomes and climatic conditions over multiyear periods. The third objective aims to address the MEP-ET model difficulty in estimating ET under very low water availability conditions. A stomatal regulation parameter is then introduced in this model to better represent the effect of water stress.

The present paper is organized as follows. Section 2 briefly reviews the MEP model proposed by Wang and Bras (2011), highlighting the differences between its two versions (MEP-Ev and MEP-Tr). The proposed MEP-ET model combining these versions is then formulated. Section 3 describes the test sites. Approximations made to calculate the MEP-ET input variables at these sites are also presented in this section. Section 4 presents the evaluation results of the MEP-ET model. Section 5 introduces a stomatal regulation parameter to improve the estimation of ET under severe water stress. Daily ET results obtained using the generalized MEPET model that includes the stomatal regulation parameter are compared with observations at the test sites, as well as with other results obtained using classic ET models.

\section{Model formulation}

\section{a. MEP model}

The formulation of the MEP solution for land surface fluxes (ground heat flux $G$, sensible heat flux $H$, and ET expressed as latent heat flux) under the constraint of energy conservation at the land surface $\left(G+H+\mathrm{ET}=R_{n}\right.$, where $R_{n}$ is net radiation at the land surface) was obtained by

1) formulating the entropy production function $D$ in terms of surface fluxes to characterize the physics behind ET, including turbulent transport in the atmospheric boundary layer;

2) finding the stationary point of $D$ in terms of surface fluxes under the constraint of energy conservation; and

3) numerically solving the surface fluxes given three input variables: $R_{n}$, surface temperature $T_{s}$, and surface specific humidity $q_{s}$.

The entropy production function $D$ that is derived from the MEP theory (Wang and Bras 2009, 2011) is expressed as follows: 


$$
D(G, H, \mathrm{ET})=\frac{2 G^{2}}{I_{s}}+\frac{2 H^{2}}{I_{a}}+\frac{2 \mathrm{ET}^{2}}{I_{e}},
$$

where $I_{s}, I_{a}$, and $I_{e}$ are the thermal inertia parameters associated with the corresponding fluxes $(G, H$, and $\mathrm{ET}$, respectively). The entropy production function $D$ may be understood using the analogy of an electrical circuit where the electric current and conductance corresponds to land surface fluxes and thermal inertia parameters, respectively (Wang et al. 2013). The thermal inertia parameters $\left(I_{s}, I_{a}\right.$, and $\left.I_{e}\right)$ are key elements of $D$. Parameter $I_{s}$ characterizes the thermal property of the land surface (appendix A). Parameter $I_{a}$, which characterizes the turbulent heat transfer in the air, is derived using an extremum solution of the Monin-Obukhov similarity theory (MOST; Wang and Bras 2009, 2010). Parameter $I_{e}$ is associated with the turbulent transport of water vapor and is related with $I_{a}$ through

$$
I_{e}=\sigma I_{a},
$$

where $\sigma$ is a dimensionless parameter. The expression of this parameter is postulated by Wang and Bras (2011) based on the Edlefsen and Anderson (1943, p. 141) formulation, as follows:

$$
\sigma\left(T_{s}, q_{s}\right) \equiv \frac{\sqrt{\alpha} \lambda^{2}}{c_{p} R_{v}} \frac{q_{s}}{T_{s}^{2}},
$$

where $c_{p}$ is specific heat of the air at constant pressure $\left(\mathrm{J} \mathrm{kg}^{-1} \mathrm{~K}^{-1}\right), R_{v}$ is the gas constant for water vapor $\left(\mathrm{J} \mathrm{kg}^{-1} \mathrm{~K}^{-1}\right), \alpha$ is the ratio of the eddy diffusivities for water vapor and heat, and $\lambda$ is the latent heat of vaporization of liquid water $\left(\mathrm{J} \mathrm{kg}^{-1}\right)$. As emphasized by Wang and Bras (2011), the expression of $\sigma$, as a function of $T_{s}$ and $q_{s}$, is postulated (assumed) and not derived from physics. This implies that its validity can only be confirmed by a correct prediction of ET.

Depending on the application surface (soil surface or leaf surface), two versions of the MEP model can be distinguished. These versions will be presented in the following subsections. Hereafter, for the purpose of clarity, $T_{s}$ and $q_{s}$, which designate surface temperature and surface humidity, respectively, will be replaced by $T_{\mathrm{ss}}$ and $q_{\mathrm{ss}}$ for the case of soil surface and by $T_{\mathrm{ls}}$ and $q_{\mathrm{ls}}$ for the case of leaf surface.

\section{1) MEP-EV}

Over nonvegetated surfaces, ET consists of only bare soil evaporation (Ev), and as such, the MEP-Ev version of the approach is used. In this case, the parameter $\sigma$ is a function of soil surface temperature $T_{\mathrm{ss}}$ and soil surface specific humidity $q_{\mathrm{ss}}$ :

$$
\sigma=\sigma\left(T_{\mathrm{ss}}, q_{\mathrm{ss}}\right) .
$$

Using this expression, Ev $\left(\mathrm{W} \mathrm{m}^{-2}\right)$ is thus obtained by solving the following nonlinear equations:

$$
\left\{\begin{array}{l}
\mathrm{Ev}=B(\sigma) H \\
R_{n}=H\left[1+B(\sigma)+\frac{B(\sigma)}{\sigma} \frac{I_{s}}{I_{0}}|H|^{1 / 6}\right],
\end{array}\right.
$$

where $B(\sigma)$ is the reciprocal Bowen ratio (inverse of the Bowen ratio) expressed as:

$$
B(\sigma)=6\left(\sqrt{1+\frac{11}{36} \sigma}-1\right) .
$$

Equation (5) constitutes the basis of the MEP-Ev version of the MEP model.

\section{2) MEP-TR}

Over fully vegetated surfaces, only transpiration (Tr) is taken into account for the estimation of ET. In this case, the MEP-Tr version of the model is applied. This version is derived as a special case of the MEP-Ev model, for which ground heat flux $G$ is negligible compared to sensible and latent heat fluxes $(H$ and $T r)$ at the leaf scale. The energy balance equation for fully vegetated surfaces is then approximated as $\operatorname{Tr}+H=R_{n}$. The system of equations associated with the MEP-Tr model becomes

$$
\left\{\begin{array}{c}
\operatorname{Tr}=\frac{R_{n}}{1+B^{-1}(\sigma)}, \\
H=\frac{R_{n}}{1+B(\sigma)}
\end{array}\right.
$$

where all variables and parameters in this system of equations are the same as those defined earlier for soil surfaces. The only difference is that $\sigma$ is calculated based on leaf surface specific humidity $q_{\mathrm{ls}}$ and leaf surface temperature $T_{\mathrm{ls}}$ :

$$
\sigma=\sigma\left(T_{\mathrm{ls}}, q_{\mathrm{ls}}\right)
$$

\section{b. The MEP-ET model (combining MEP-Ev and $M E P-T r)$}

The use of MEP-Ev and MEP-Tr models is restricted to specific sites (either bare soil or fully vegetated surfaces) and periods (e.g., postharvest and growing season). In a broad range of sites, the surface can be partially vegetated, and as such, evapotranspiration consists of soil evaporation as well as plant transpiration. The relative importance of each process is dynamic, 
following bioclimatic controls. To estimate the total water vapor transfer to the atmosphere (ET), it is therefore necessary to combine MEP-Ev and MEP-Tr. This may be achieved by using a vegetation index $f_{\text {veg }}$ defined as the fraction of soil covered with vegetation. Index $f_{\text {veg }}$ varies between 0 (bare soil) and 1 (fully covered vegetation). When evaporation from intercepted rainfall is neglected, as assumed in this work, one obtains the MEP-ET model calculating ET as

$$
\mathrm{ET}=\left(1-f_{\mathrm{veg}}\right) \mathrm{Ev}+f_{\mathrm{veg}} \mathrm{Tr},
$$

where Ev and $\mathrm{Tr}$ are soil evaporation (obtained using MEP-Ev) and plant transpiration (obtained using MEP-Tr), respectively. In Eq. (9), the vegetation index $f_{\text {veg }}$ may be determined using the normalized difference vegetation index (NDVI), as it is an indicator of the chlorophyll activity of the vegetation (Pontailler et al. 2003; Qi et al. 2000; Spanner et al. 1990). The NDVI takes into account the difference between red and nearinfrared reflectance of vegetation canopies to assess the presence of green vegetation. Note that vegetation preferentially absorbs solar radiation in the red portion of the light spectrum for photosynthesis and strongly reflects it in the near infrared. The NDVI thus reflects the balance between the energy received and emitted by vegetation. Following Wittich and Hansing (1995), $f_{\text {veg }}$ is taken here as

$$
f_{\mathrm{veg}}=\frac{\mathrm{NDVI}-\mathrm{NDVI}_{\text {min }}}{\mathrm{NDVI}_{\text {max }}-\mathrm{NDVI}_{\text {min }}},
$$

where $\mathrm{NDVI}_{\max }$ and $\mathrm{NDVI}_{\min }$ correspond to NDVI values for dense vegetation and bare soil, respectively. In this study, $f_{\text {veg }}$ is calculated on a weekly scale with NDVI data from Landsat images obtained through the USGS Earth Explorer platform (earthexplorer.usgs. gov). Daily $f_{\text {veg }}$ is obtained by linear interpolation of the weekly $f_{\text {veg }}$ data. Estimation of ET using $f_{\text {veg }}$ will be evaluated at eight sites from different biomes and with different climatic conditions. A description of the test sites is given in the next section.

\section{Data}

\section{a. Study sites}

For a comprehensive evaluation of the MEP-ET model [Eq. (9)], particular attention is given to the spatial and temporal coherence of its calculations. For this purpose, FLUXNET datasets (Baldocchi et al. 2001; Agarwal et al. 2010) were selected. They provide highquality eddy covariance measurements of surface fluxes and ancillary meteorological variables. The selected eight FLUXNET sites (http://ameriflux.ornl.gov) are from different biomes: grassland (GRA), cropland (CRO), woody savanna/shrubland (WSA), and deciduous broadleaved (DBF) and evergreen needleleaf (ENF) forests. The selected sites are located in the continental United States (Fig. 1) with a range of vegetation covers, climates, precipitation regimes, altitudes, and canopy heights (see Table 1). ENF1 (evergreen forest site) is characterized by Mediterranean climate, where ET corresponds to $45 \%$ of the annual precipitation $(1294 \mathrm{~mm}) . \mathrm{DBF} 1$ and DBF2 (deciduous broadleaved forests sites) present a temperate climate. A humid continental climate is found at CRO1 and CRO2 (cropland sites) and GRA2 (grassland site); and a semiarid climate is found at GRA1 (grassland site) and WSA1 (woody savanna site), where ET exceeds $80 \%$ of the annual precipitation.

To characterize each site in terms of its mean limiting factors for ET, namely, available energy "demand" (net radiation) and water "supply" (precipitation), the nondimensional framework proposed by Budyko (1974) is used (Fig. 2). This framework is based on the radiative dryness (DI) and evaporative (EI) indices. DI is defined as a ratio of potential evapotranspiration (PET), estimated following Priestley and Taylor (1972), and observed precipitation. On the other hand, EI is expressed as the ratio between the observed evapotranspiration and precipitation. These indices are represented at climatological time scales by averaging over multiple years. As shown in Fig. 2, the sites are distributed in space with large demand/supply differences, while still clustered around the Budyko curve. The majority of sites are under moderate water availability, except for GRA2. Two sites (WSA1, GRA1) are located in arid regions $(\mathrm{PET}>3 P)$. The DBF2 site is similar to the latter sites, except it experienced some much drier years (see bottom-right corner of Fig. 2). Drought and nondrought conditions needed to be defined at this site. The transition from a nondrought to drought regime occurs when plant water potential falls below $-0.7 \mathrm{MPa}$, based on an analysis of $\mathrm{Gu}$ et al. (2006) at the same site.

\section{b. MEP-ET input variables}

In brief, model inputs needed to run MEP-ET include net radiation $R_{n}$, soil surface temperature $T_{\mathrm{ss}}$, and specific humidity $q_{\mathrm{ss}}$, as well as leaf surface temperature $T_{\mathrm{ls}}$ and leaf specific humidity $q_{\mathrm{ls}}$. Given that these variables are rarely directly measured, approximations were made. In this study, soil temperature, typically measured at depths between 2 and $10 \mathrm{~cm}$ depending on the site, is taken as a surrogate of soil surface temperature $T_{\mathrm{ss}}$. Soil surface specific humidity $q_{\mathrm{ss}}$ is approximated as air 


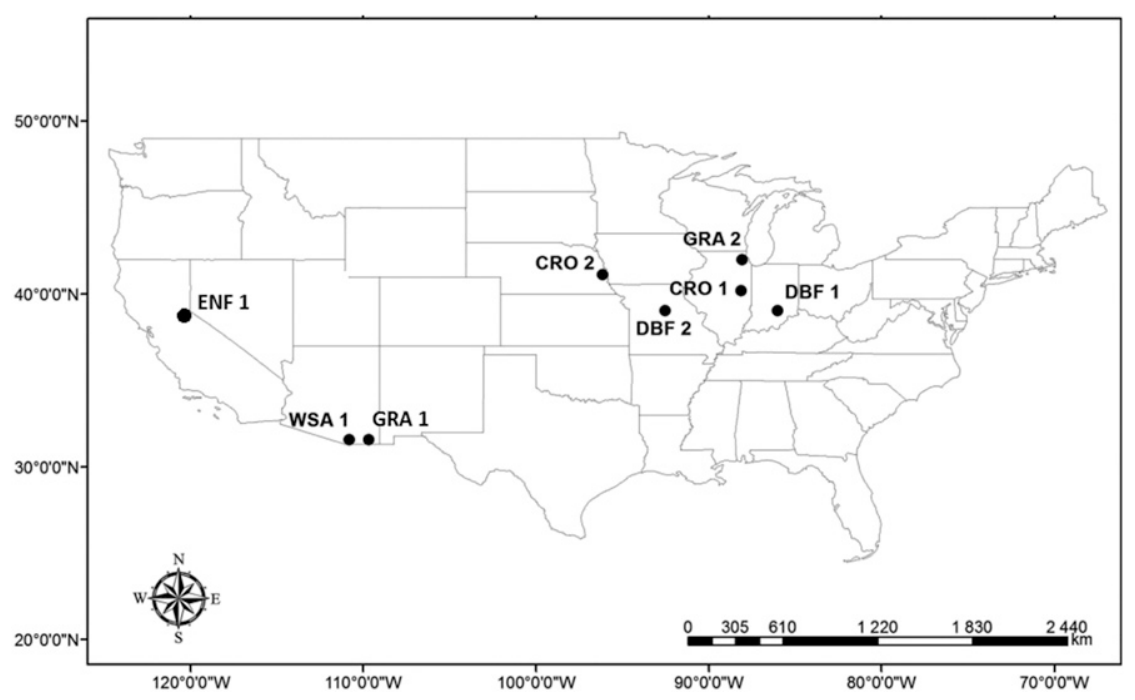

FIG. 1. Location of the selected FLUXNET sites.

specific humidity at near soil surface, which is calculated using the well-known Clausius-Clapeyron equation with $T_{\mathrm{ss}}$ and relative humidity $(\mathrm{RH})$ measured at near soil surface. Furthermore, observations of temperature and relative humidity within the canopy (when available) or closest to the canopy top are used to obtain $T_{\mathrm{ls}}$ and $q_{\mathrm{ls}}$, following the approach used for $T_{\mathrm{ss}}$ and $q_{\mathrm{ss}}$. Using this approach, the obtained $q_{\mathrm{ls}}$ values would be slightly underestimated compared to direct measurements at the leaf surface (as recommended by Wang and Bras 2011), which are not available at these sites.

\section{c. Model evaluation criteria}

Model outputs in terms of daily ET are compared against observations at the eight sites of interest throughout this analysis. Given that most evapotranspiration occurs during daytime and that the observed energy imbalance is often greater at night (Wilson et al. 2002), estimations and observations of daily evapotranspiration are determined by cumulating 30-min values (estimated or observed) from 0700 to 1800 local time. The following sets of metrics are used to assess model performance: Nash-Sutcliffe efficiency (NSE), percent bias (PB), root-mean-square error (RMSE), and the coefficient of determination $R^{2}$ (Ershadi et al. 2014; Pereira et al. 2015).

\section{Evaluation of the MEP-ET model}

As shown in Table 2, MEP-ET model performance varies from site to site. The mean RMSE ranges from $0.53 \mathrm{~mm} \mathrm{day}^{-1}$ at ENF1 to $0.71 \mathrm{~mm} \mathrm{day}^{-1}$ at DBF2, with an average value of $0.62 \mathrm{~mm} \mathrm{day}^{-1}$ for all sites. In 2007, the RMSE value exceeded $0.94 \mathrm{~mm} \mathrm{day}^{-1}$ at DBF2. On average, the MEP-ET model explains $80 \%$ of the observed ET variations at all sites, ranging from $63 \%$ at GRA1 to a high of $87 \%$ at DBF1. An average PB of $10 \%$ was obtained for all sites and ranged from $3 \%$ at ENF to $1 \%-60 \%$ at GRA1. In 2009 , PB exceeded $85 \%$ at GRA1. In addition, the mean NSE is highly variable,

TABLE 1. Main characteristics of the test sites. Parameter $z_{g}$ represents the elevation above mean sea level, $z_{c}$ is the mean canopy height, $P$ is the mean annual precipitation, and ET is the mean annual evapotranspiration. Koppen climate classes are humid continental (Dfa), humid subtropical (Cfa), Mediterranean (Csa), and semiarid climate (Bsk).

\begin{tabular}{lccrrrrrr}
\hline \hline Site & FLUXNET code & Coordinates & $z_{g}(\mathrm{~m})$ & $z_{c}(\mathrm{~m})$ & $P\left(\mathrm{~mm} \mathrm{yr}^{-1}\right)$ & ET $\left(\mathrm{mm} \mathrm{yr}^{-1}\right)$ & Years & Koppen climate class \\
\hline CRO1 & US-Bo1 & $40.0^{\circ} \mathrm{N}, 88.3^{\circ} \mathrm{W}$ & 219 & 3.0 & 860 & 722 & $2003-07$ & Dfa \\
CRO2 & US-Ne3 & $41.2^{\circ} \mathrm{N}, 96.4^{\circ} \mathrm{W}$ & 363 & 2.5 & 729 & 582 & $2003-12$ & Dfa \\
GRA1 & US-Wkg & $31.7^{\circ} \mathrm{N}, 109.9^{\circ} \mathrm{W}$ & 1531 & 0.5 & 302 & 248 & $2007-12$ & Bsk \\
GRA2 & US-IB2 & $41.8^{\circ} \mathrm{N}, 88.2^{\circ} \mathrm{W}$ & 226 & - & 1011 & 650 & $2006-10$ & Dfa \\
DBF1 & US-MMS & $39.3^{\circ} \mathrm{N}, 86.4^{\circ} \mathrm{W}$ & 275 & 27.0 & 1094 & 472 & $2001-06$ & Cfa \\
DBF2 & US-MOz & $38.7^{\circ} \mathrm{N}, 92.2^{\circ} \mathrm{W}$ & 219 & 24.0 & 992 & 635 & $2005-10$ & Cfa \\
ENF1 & US-Blo & $38.9^{\circ} \mathrm{N}, 120.6^{\circ} \mathrm{W}$ & 1315 & 4.0 & 1294 & 577 & $2001-05$ & Csa \\
WSA1 & US-SRM & $31.8^{\circ} \mathrm{N}, 110.9^{\circ} \mathrm{W}$ & 1116 & 2.5 & 310 & 286 & $2004-08$ & Bsk \\
\hline
\end{tabular}




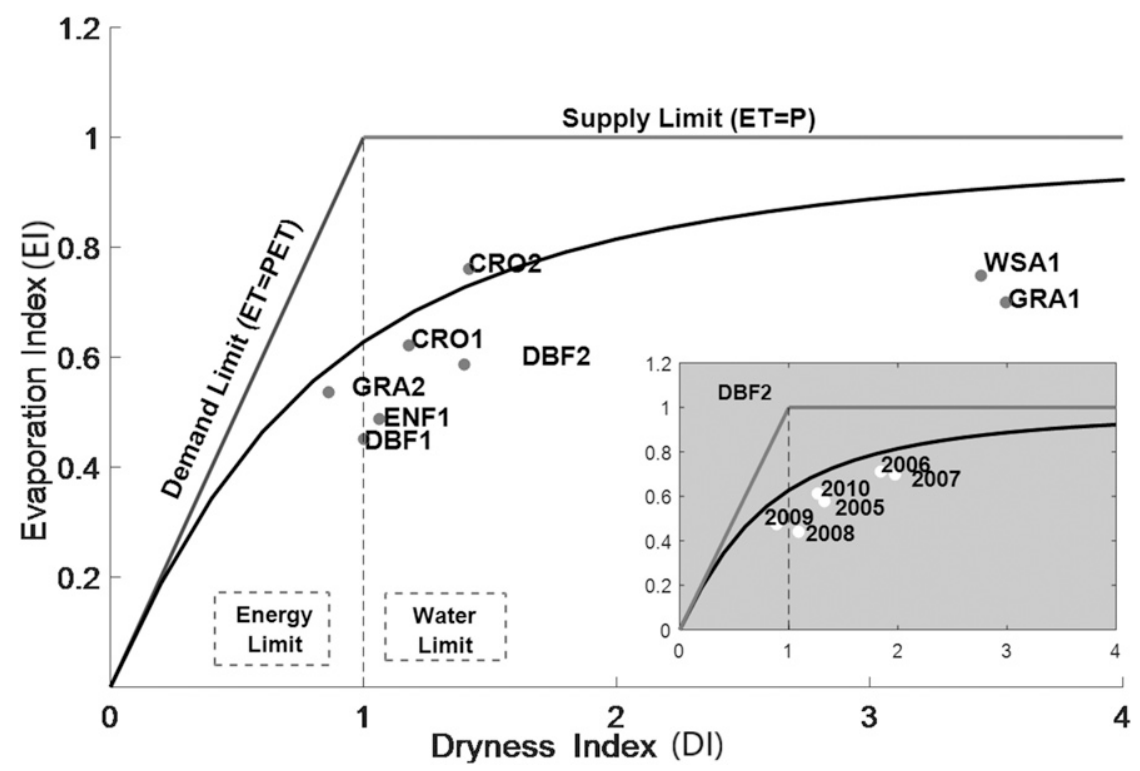

FIG. 2. Mean EI as a function of the mean DI. The black solid curve is from Budyko (1974). Year-to-year variability is shown for DBF2 exclusively in the bottom right corner. Adapted from Williams et al. (2012).

being 0.23 and 0.33 at GRA1 and WSA1, respectively, and 0.84 at ENF1 with 0.79 as an average value for all sites. High values of NSE were recorded at GRA2 (0.90 in 2010) and ENF1 (0.86 in 2003), demonstrating the capability of MEP-ET to reproduce observed ET at these sites. Occasional negative NSE values were obtained at WSA1 $(-0.30$ in 2004) and GRA1 $(-0.52$ in 2009). Sample daily values of estimated and observed

TABLE 2. Performance values of the MEP-ET model in terms of NSE, $R^{2}$, PB (\%), and RMSE (mm day ${ }^{-1}$ ) at all study sites.

\begin{tabular}{|c|c|c|c|c|c|c|c|c|c|c|c|}
\hline Sites & Year & NSE & $R^{2}$ & PB & RMSE & Sites & Year & NSE & $R^{2}$ & $\mathrm{~PB}$ & $\overline{\text { RMSE }}$ \\
\hline \multirow[t]{6}{*}{ CRO1 } & 2003 & 0.75 & 0.79 & 14 & 0.54 & \multirow[t]{6}{*}{ DBF1 } & 2001 & 0.82 & 0.92 & 31 & 0.60 \\
\hline & 2004 & 0.73 & 0.75 & 1 & 0.63 & & 2002 & 0.76 & 0.89 & 37 & 0.66 \\
\hline & 2005 & 0.69 & 0.77 & 12 & 0.69 & & 2003 & 0.81 & 0.84 & 7 & 0.71 \\
\hline & 2006 & 0.85 & 0.89 & 15 & 0.51 & & 2004 & 0.85 & 0.90 & 19 & 0.53 \\
\hline & 2007 & 0.61 & 0.68 & 11 & 0.75 & & 2005 & 0.82 & 0.89 & 26 & 0.62 \\
\hline & All years & 0.73 & 0.75 & 4 & 0.63 & & All years & 0.82 & 0.87 & 24 & 0.61 \\
\hline \multirow[t]{5}{*}{$\mathrm{CRO} 2$} & 2003 & 0.85 & 0.87 & 7 & 0.56 & \multirow[t]{5}{*}{ DBF2 } & 2005 & 0.75 & 0.80 & 14 & 0.66 \\
\hline & 2004 & 0.73 & 0.74 & 9 & 0.76 & & 2006 & 0.71 & 0.78 & 21 & 0.72 \\
\hline & 2005 & 0.82 & 0.83 & 7 & 0.65 & & 2007 & 0.49 & 0.68 & 37 & 0.94 \\
\hline & 2006 & 0.78 & 0.78 & 2 & 0.69 & & 2008 & 0.83 & 0.84 & 4 & 0.65 \\
\hline & All years & 0.82 & 0.82 & 5 & 0.65 & & 2009 & 0.85 & 0.86 & 2 & 0.61 \\
\hline \multirow[t]{6}{*}{ GRA1 } & 2007 & -0.25 & 0.56 & 67 & 0.62 & \multirow{6}{*}{ ENF1 } & All years & 0.77 & 0.80 & 13 & 0.71 \\
\hline & 2008 & 0.23 & 0.75 & 69 & 0.59 & & 2001 & 0.84 & 0.84 & 2 & 0.48 \\
\hline & 2009 & -0.52 & 0.45 & 85 & 0.62 & & 2002 & 0.85 & 0.85 & 5 & 0.56 \\
\hline & 2010 & 0.34 & 0.62 & 38 & 0.54 & & 2003 & 0.86 & 0.86 & 5 & 0.46 \\
\hline & 2011 & 0.40 & 0.67 & 69 & 0.53 & & 2004 & 0.79 & 0.80 & 5 & 0.57 \\
\hline & All years & 0.23 & 0.63 & 60 & 0.57 & & 2005 & 0.82 & 0.83 & 6 & 0.62 \\
\hline \multirow[t]{7}{*}{ GRA2 } & 2006 & 0.70 & 0.73 & 12 & 0.75 & \multirow{7}{*}{ WSA1 } & All years & 0.84 & 0.84 & 3 & 0.53 \\
\hline & 2007 & 0.86 & 0.88 & 8 & 0.57 & & 2004 & -0.30 & 0.54 & 65 & 0.60 \\
\hline & 2008 & 0.86 & 0.88 & 8 & 0.55 & & 2005 & 0.26 & 0.60 & 50 & 0.60 \\
\hline & 2009 & 0.84 & 0.84 & 5 & 0.53 & & 2006 & 0.33 & 0.67 & 59 & 0.58 \\
\hline & 2010 & 0.90 & 0.90 & 6 & 0.45 & & 2007 & 0.21 & 0.65 & 63 & 0.63 \\
\hline & All years & 0.83 & 0.84 & 4 & 0.58 & & 2008 & 0.65 & 0.79 & 39 & 0.53 \\
\hline & & & & & & & All years & 0.33 & 0.67 & 54 & 0.59 \\
\hline Average & All sites & 0.79 & 0.80 & 10 & 0.62 & & & & & & \\
\hline
\end{tabular}





FIG. 3. Daily variation of estimated (using MEP-ET) vs observed ET at the sites of interest. In the $x$-axis label, the three first letters represent the month, while the two numbers represent the year. In both cases (modeled and observed values), a 10-day running average was used to smooth the data.

ET at all sites confirm the above findings (Fig. 3). As shown in Fig. 3, the MEP-ET model captures very well the seasonal cycle of observed ET at the CRO1, GRA2, DBF1, ENF1, and CRO2 sites, which are characterized by unlimited to moderate water availability (Fig. 2). On the contrary, poor results were obtained at the GRA1 $(\mathrm{PB}=85 \%$ in 2009$)$, WSA1 $(\mathrm{PB}=63 \%$ in 2007$)$, and DBF2 (NSE $=0.49$ in 2007) sites, which are characterized by low water availability (Fig. 2). The MEP-ET model tends to overestimate the daily ET at these sites (Fig. 3), particularly during low soil moisture periods (Fig. 4). Note that this issue has also been raised in other studies relying on classic ET models under similar circumstances (Hari and Kulmala 2008; Ji et al. 2017). As shown in Fig. 4, periods of very low soil moisture are characterized by the transpiration fraction of ET exceeding $80 \%$ and $90 \%$ at the GRA1 and DBF2 sites, respectively. This reveals that the overestimation of ET arises from an inaccurate treatment of transpiration. First, one could think that this is the outcome to a poor estimation of $q_{\mathrm{ls}}$, the leaf surface specific humidity, in the computation of total ET. However, as explained in section 3, direct measurements of $q_{\mathrm{ls}}$ would necessarily result in an even larger overestimation of ET. Indeed, measured $q_{\mathrm{ls}}$ at leaf surface would be slightly higher than estimated $q_{\mathrm{ls}}$, obtained using air temperature and specific humidity closest to the canopy top, leading to larger ET overestimation.
Therefore, the mechanism responsible for this overestimation has to be the stomatal control of ET. Indeed, the stomata tend to close under dry conditions to prevent water loss, hence reducing transpiration. The stomatal control of water vapor loss by transpiration is increasingly accentuated as water stress increases (Hari and Kulmala 2008; Berry et al. 2010; Ji et al. 2017). Although the effect of stomatal closure is implicitly parameterized in the MEP-ET model through $q_{\mathrm{ls}}$ resulting from water vapor loss by transpiration, the above analysis suggests that this parameterization would not be sufficient under high water stress conditions. In the next section, a new parameterization for the stomatal control of leaf water loss is proposed to further improve the performance of the MEP-ET model.

\section{Modeling ET under water stress conditions: The generalized MEP-ET model}

\section{a. Water stress factor $\eta_{s}$}

To overcome the problem of ET overestimation under water stress conditions within the framework of classic ET models, several researchers have proposed a water stress factor in the parameterization of stomatal conductance (Sala and Tenhunen 1996; Wang and Leuning 1998; Van Wijk et al. 2000; Tuzet et al. 2003; Misson et al. 2004; Uddling et al. 2005; Müller et al. 2014; Ji et al. 2017). Following this path, the effect of water stress has to be better represented in the MEP-ET model to improve 

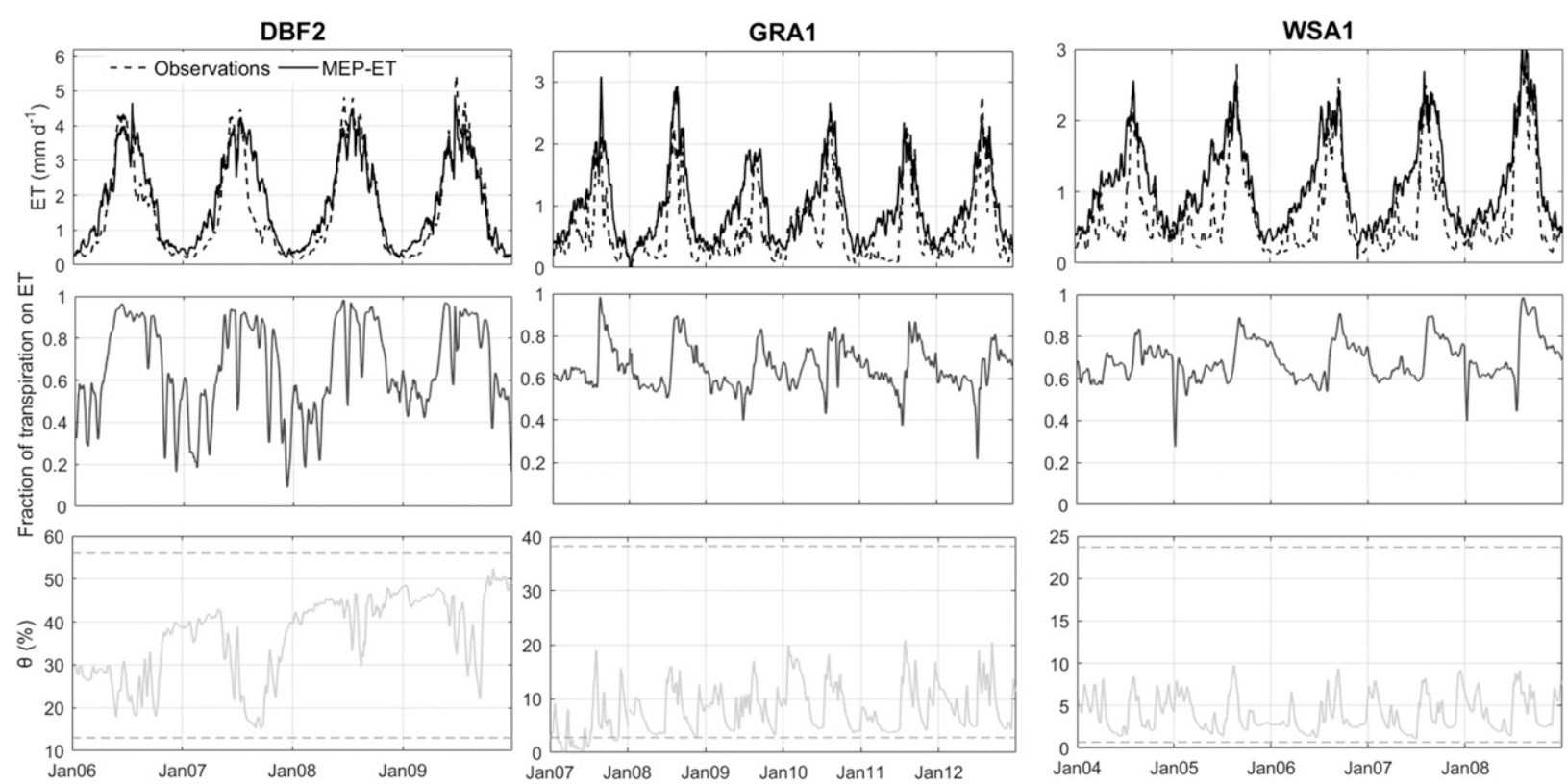

FIG. 4. A close look at the issue of overestimated ET using MEP-ET under water stress conditions at the DBF2, GRA1, and WSA1 sites. (top) Model outputs from MEP-ET along with observations, (middle) the transpiration fraction, and (bottom) time series of soil moisture. The dashed lines in the bottom plots represent the upper (field capacity) and lower (wilting point) limits of soil moisture variability. In the $x$-axis label, the three first letters represent the month, while the two numbers represent the year. In both cases (modeled and observed values), a 10-day running average was used to smooth the data.

its performance for water-limited environments while maintaining its advantageous features.

As stated by Wang and Bras (2011), the expression of $\sigma$ [Eq. (3)] is not derived from physics and, as such, its validity can only be confirmed through the correct prediction of ET, which is obviously not the case at vegetated sites under severe water stress conditions (section 4). Thus, the present work proposes to include a water stress factor in $\sigma$, such that

$$
\sigma\left(T_{\mathrm{ls}}, q_{\mathrm{ls}}, \eta_{s}\right) \equiv \eta_{s} \frac{\sqrt{\alpha} \lambda^{2}}{c_{p} R_{v}} \frac{q_{\mathrm{ls}}}{T_{\mathrm{ls}}^{2}}
$$

where the water stress factor $\eta_{s}$ characterizes the stomatal response to water availability, that is, it represents the relative water availability for plants. Parameter $\eta_{s}$ varying from 0 (dry soil) to 1 (saturated soil) can be parameterized in terms of soil water content or soil/leaf water potential. Several empirical functions used to compute this factor can be found in the literature (Gollan et al. 1986; Wang and Leuning 1998; Tuzet et al. 2003). In this study, the following empirical function, for which inputs are available at the eight test sites, is used (Gollan et al. 1986; Wang and Leuning 1998):

$$
\eta_{s}(\theta)=\min \left[1, \frac{10\left(\theta-\theta_{\min }\right)}{3\left(\theta_{\max }-\theta_{\min }\right)}\right],
$$

where $\theta_{\max }$ and $\theta_{\min }$ are soil water contents at field capacity and wilting point, respectively, at a soil depth of at least $25 \mathrm{~cm}$. Both parameters can be readily obtained from soil characteristics. When soil type is unknown, long-term soil moisture observations may be used to estimate $\theta_{\max }$ and $\theta_{\min }$ (Calvet et al. 1998; Zotarelli et al. 2010; Ershadi et al. 2014) by taking the 99th and 1st percentiles of the distribution of soil moisture observations. Tests of the generalized MEP-ET model with the water stress factor $\eta_{s}$ as in Eq. (12) were conducted for two warm and dry sites (WSA1, GRA1) and for the DBF2 site with alternating wet and dry periods (Fig. 2).

\section{b. Performance of the generalized MEP-ET model}

Model performance metrics for the WSA1, GRA1, and DBF2 sites are summarized in Table 3. Figure 5 compares the observed and estimated daily ET from the MEP-ET and the generalized MEP-ET models (i.e., with and without $\eta_{s}$ ) at the WSA1 site. The generalized MEP-ET estimated daily ET is in much closer agreement with the observations compared to daily ET estimated using MEP-ET. For instance, both RMSE and PB were substantially reduced from 0.63 to $0.26 \mathrm{~mm} \mathrm{day}^{-1}$ and from $63 \%$ to $12 \%$, respectively, in 2007 . NSE was also much improved as it increased from 0.21 to 0.86 . Figure $5 \mathrm{~b}$ shows that the influence of $\eta_{s}$ increases as soil moisture decreases and vice versa. The influence of $\eta_{s}$ is reduced 
TABLE 3. Performance values of the MEP-ET and the generalized MEP-ET models for critical years at sites GRA1, DBF2, and WSA1.

\begin{tabular}{|c|c|c|c|c|c|c|c|c|c|}
\hline \multirow[b]{2}{*}{ Sites } & \multirow[b]{2}{*}{ Period } & \multicolumn{2}{|c|}{ NSE } & \multicolumn{2}{|c|}{$R^{2}$} & \multicolumn{2}{|c|}{ PB (\%) } & \multicolumn{2}{|c|}{$\operatorname{RMSE}\left(\mathrm{mm} \mathrm{day}^{-1}\right)$} \\
\hline & & MEP-ET & $\begin{array}{c}\text { Generalized } \\
\text { MEP-ET }\end{array}$ & MEP-ET & $\begin{array}{c}\text { Generalized } \\
\text { MEP-ET }\end{array}$ & MEP-ET & $\begin{array}{c}\text { Generalized } \\
\text { MEP-ET }\end{array}$ & MEP-ET & $\begin{array}{c}\text { Generalized } \\
\text { MEP-ET }\end{array}$ \\
\hline \multirow[t]{7}{*}{ GRA1 } & 2007 & -0.25 & 0.74 & 0.56 & 0.76 & 67 & 1 & 0.62 & 0.28 \\
\hline & 2008 & 0.23 & 0.73 & 0.75 & 0.86 & 69 & 27 & 0.59 & 0.35 \\
\hline & 2009 & -0.52 & 0.32 & 0.45 & 0.60 & 85 & 43 & 0.62 & 0.42 \\
\hline & 2010 & 0.34 & 0.72 & 0.62 & 0.77 & 38 & 11 & 0.54 & 0.36 \\
\hline & 2011 & 0.40 & 0.79 & 0.67 & 0.83 & 69 & 24 & 0.53 & 0.31 \\
\hline & 2012 & 0.54 & 0.82 & 0.73 & 0.84 & 46 & 17 & 0.50 & 0.32 \\
\hline & All years & 0.23 & 0.72 & 0.63 & 0.77 & 60 & 19 & 0.57 & 0.34 \\
\hline \multirow[t]{2}{*}{ DBF2 } & Drought & 0.19 & 0.68 & 0.47 & 0.69 & 25 & 5 & 1.12 & 0.70 \\
\hline & All years & 0.77 & 0.83 & 0.80 & 0.83 & 13 & 6 & 0.71 & 0.61 \\
\hline \multirow[t]{6}{*}{ WSA1 } & 2004 & -0.30 & 0.71 & 0.54 & 0.76 & 65 & 13 & 0.60 & 0.28 \\
\hline & 2005 & 0.26 & 0.70 & 0.60 & 0.70 & 50 & 0 & 0.60 & 0.38 \\
\hline & 2006 & 0.33 & 0.80 & 0.67 & 0.81 & 59 & 7 & 0.58 & 0.32 \\
\hline & 2007 & 0.21 & 0.86 & 0.65 & 0.88 & 63 & 12 & 0.63 & 0.26 \\
\hline & 2008 & 0.65 & 0.90 & 0.79 & 0.91 & 39 & 2 & 0.53 & 0.28 \\
\hline & All years & 0.33 & 0.82 & 0.67 & 0.82 & 54 & 6 & 0.59 & 0.31 \\
\hline
\end{tabular}

(Fig. 5b) when rain events increase water supply during the growing season (e.g., in July). Similar conclusions can be drawn from tests at the GRA1 and DBF2 sites. Figure 6 shows the observed and estimated cumulative daily ET over six consecutive years at the GRA1 site. The MEP-ET model overestimates cumulative daily ET by $796 \mathrm{~mm}(\mathrm{~PB}=65 \%)$, which corresponds to $44 \%$ of the cumulative precipitation $(1800 \mathrm{~mm})$ over the same period. This overestimation is reduced to only $250 \mathrm{~mm}$ when the generalized MEP-ET model is used. Figure 7 compares the observed and modeled daily ET over four consecutive years at the DBF2 site. Although DBF2 is a wet site with an annual rainfall of approximately $1000 \mathrm{~mm}$, it experienced dry periods in some years (for instance, $630 \mathrm{~mm}$ in 2007). Application of the generalized MEP-ET model provided accurate estimates of ET for all years, even for wet periods. An estimated gain of $61 \%$ in terms of NSE was obtained compared to the MEP-ET model. Note that the generalized MEP-ET performs equally well for wet periods (e.g., 2008). This shows its applicability to general water stress conditions. Figure 8 confirms this finding using the comparison between the observed and estimated daily ET using the generalized MEP-ET model at all study sites and over the entire test period. Overall, the model performs very well $(\mathrm{NSE}=$ $0.83, \mathrm{~PB}=3 \%$ ) since it captures the interannual variability at sites with contrasting climates. On the contrary, the MEP-ET model (without $\eta_{s}$ ) only performs well under well-watered to moderately water-limited conditions.

\section{c. Performance of the generalized MEP-ET model versus classic ET models}

In this section, the performance of the generalized MEP-ET model is compared with three classic ET models: the modified Penman-Monteith (PM; Brutsaert 2005; Ershadi et al. 2014), the modified PriestleyTaylor-Jet Propulsion Laboratory (PT-JPL; Fisher et al. 2008; Ershadi et al. 2014), and the air-relativehumidity-based two-source model (ARTS; Yan et al. 2012). It should be emphasized that these models take into account the effect of water stress on daily ET estimation (see appendix B for more details about the description and formulation of these models). Figure 9 shows the NSE, $R^{2}$, PB (\%), and RMSE $\left(\mathrm{mm} \mathrm{day}^{-1}\right)$ for all of the four models at the eight study sites. It is evident that the generalized MEP-ET model outperforms the other three models (PM, PT-JPL, ARTS) at all sites (biomes), as high values of NSE $(\geq 0.73)$ and $R^{2}(\geq 0.75)$ and low values of RMSE $\left(\leq 0.6 \mathrm{~mm} \mathrm{day}^{-1}\right)$ and PB $(\leq 20 \%)$ were obtained across all sites. On the contrary, using the three other models, high values of RMSE (generally larger than 0.6) and low values of NSE (generally lower than 0.7) were found. Moreover, the generalized MEP-ET model consistently performs well across all sites, while the other models do not. The NSE and $R^{2}$ values associated with the generalized MEP-ET model have relatively narrow ranges of $0.73-0.84$ and $0.75-0.87$, respectively. In contrast, the NSE values of the other models vary from 0.32 to 0.81 , and the $R^{2}$ values range from 0.40 to 0.82 . No model, other than the generalized MEP-ET model, is consistently robust for the different biomes studied. For instance, the ARTS model has the highest RMSE value $\left(\approx 1 \mathrm{~mm}\right.$ day $\left.^{-1}\right)$ at the GRA2 and CRO2 sites, whereas it has the lowest RMSE value $\left(\approx 0.42 \mathrm{~mm} \mathrm{day}^{-1}\right)$ at the GRA1 site. At the latter site, the worst performance is obtained with the PT-JPL model (NSE $=0.32$ and $R^{2}=0.4$ ), while this same model records the best performance compared to 


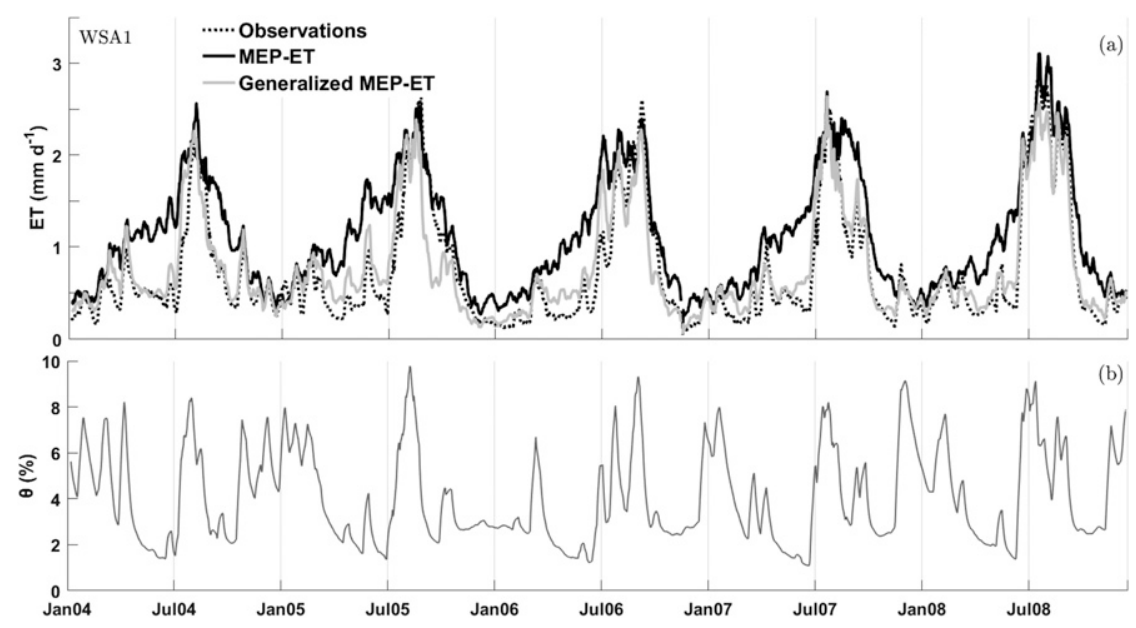

FIG. 5. (a) Comparison of ET simulated by the MEP-ET and the generalized MEP-ET models along with observations at site WSA1. (b) Temporal variation of volumetric water content $\theta$ for the same site and period. In the $x$-axis label, the three first letters represent the month, while the two numbers represent the year. In both cases (modeled and observed values), a 10-day running average was used to smooth the data.

PM and ARTS models at GRA2. For the PM model, the worst performance occurred at ENF1 (NSE = $0.32)$, whereas the best performance $\left(R^{2}=0.85\right)$ was at the DBF1 site. The above findings concerning the PM and PT-JPL models agree with earlier studies (e.g., Ershadi et al. 2014). In addition to their fluctuating performances, the classical models generally require more input data, potentially adding large uncertainty (Massman and Lee 2002; Williams et al. 2009; Ershadi et al. 2013, 2014, 2015), which makes their application difficult. Therefore, the generalized MEP-ET stands out as a promising new method for the estimation of ET, since it uses less input data than classic ET models and provides consistently better ET estimates across diverse geographical and climatic conditions.

\section{Conclusions}

This study evaluated the capability of the MEP model for simulating evapotranspiration under various climatic and vegetation conditions. A weighting coefficient was introduced to combine its two versions for modeling evaporation at nonvegetated surfaces (MEP-Ev) and transpiration at fully vegetated surfaces (MEP-Tr), resulting in the MEP-ET model. This

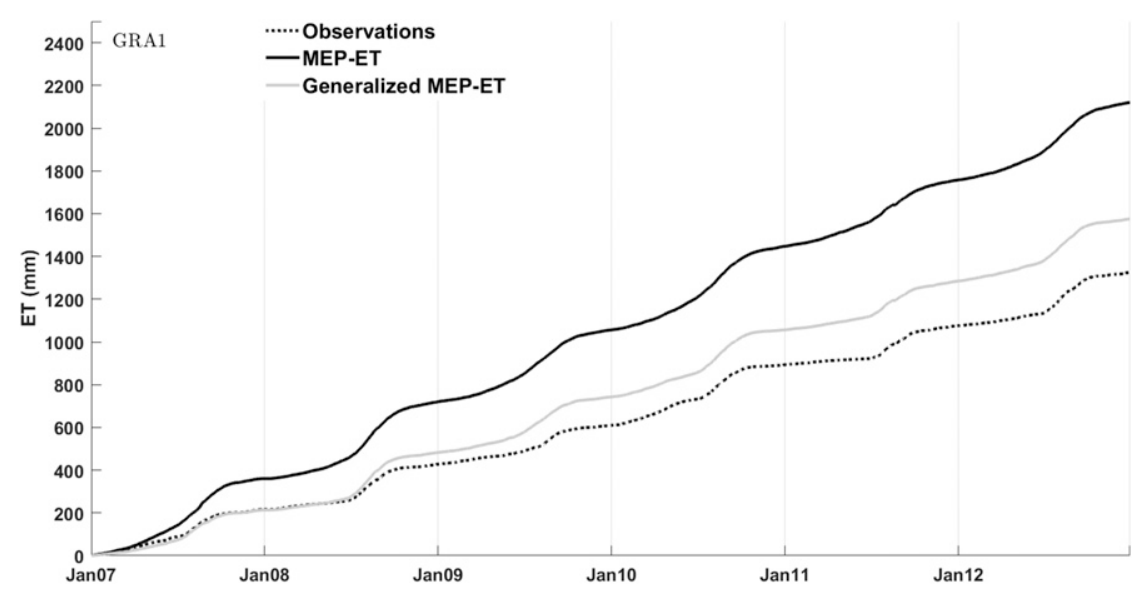

FIG. 6. Cumulative ET using observations (black dotted curve), as well as the MEP-ET and generalized MEP-ET models at site GRA1. The scores of performance of MEP-ET (black solid curve) are NSE $=-0.59, \mathrm{~PB}=65 \%$, and $\mathrm{RMSE}=478 \mathrm{~mm}$, whereas for the generalized MEP-ET (gray solid curve), they are NSE $=0.86, \mathrm{~PB}=18 \%$, and $\mathrm{RMSE}=143 \mathrm{~mm}$ for all years. 


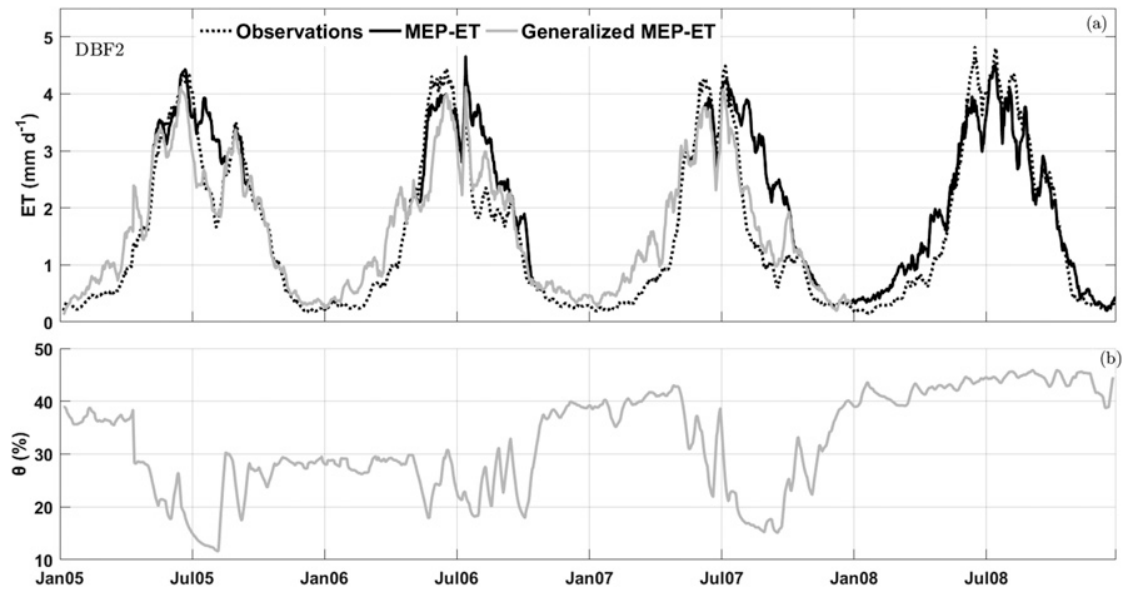

FIG. 7. (a) The 10-day averages of ET simulated by the generalized MEP-ET model, MEP-ET, and observations at site DBF2. (b) Temporal variation of soil moisture $\theta$ at site DBF2. In the $x$-axis label, the three first letters represent the month while the two numbers represent the year. In both cases (modeled and observed values), a 10-day running average was used to smooth the data.

coefficient, which characterizes the vegetation cover, is calculated using NDVI data. The MEP-ET model was evaluated at eight sites in different biomes and under different climatic conditions, including canopy water stress, for which the MEP model has never been evaluated. The MEP-ET model performs well under unlimited and moderate water availability. The overestimation of ET under water-stressed conditions can be corrected by a soil-moisture-dependent water stress function representing stomatal response to water stress. The MEP model including the water stress function greatly improved the modeled ET under dry conditions (e.g., WSA1 and GRA1 sites) and much reduced the overestimation of cumulative ET. The performance of the generalized MEP-ET model is compared to three classic ET models (PM, PT-JPL, and ARTS) at the eight sites. This comparison shows that the generalized MEP-ET model consistently outperforms the other models at all test sites. The effectiveness of the MEP model, which is based on the Bayesian probability, information theories, and boundary layer turbulence theory, results from (explicit and implicit) parameterization of all important physical mechanisms at the desired space-time scales and from more efficient use of hydrometeorological data than other physically based models.

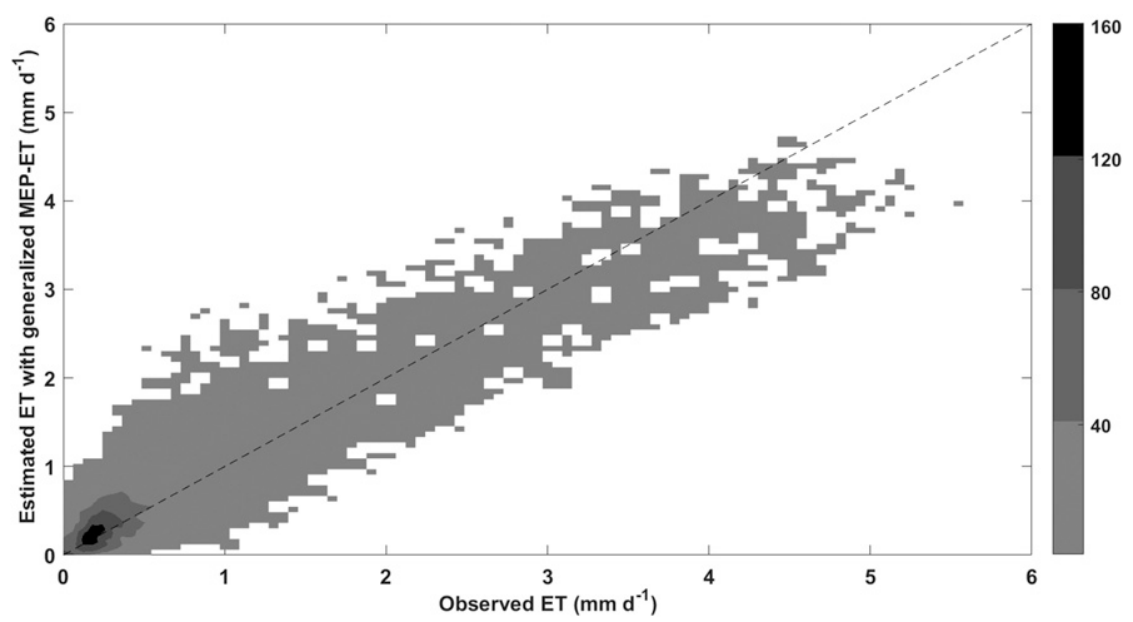

FIG. 8. Comparison of the generalized MEP-ET estimated and observed daily averaged ET at all sites and for all years under study. The color scale indicates the number of occurrences. Scores of performance are NSE $=0.83$ and $\mathrm{PB}=3 \%$. 

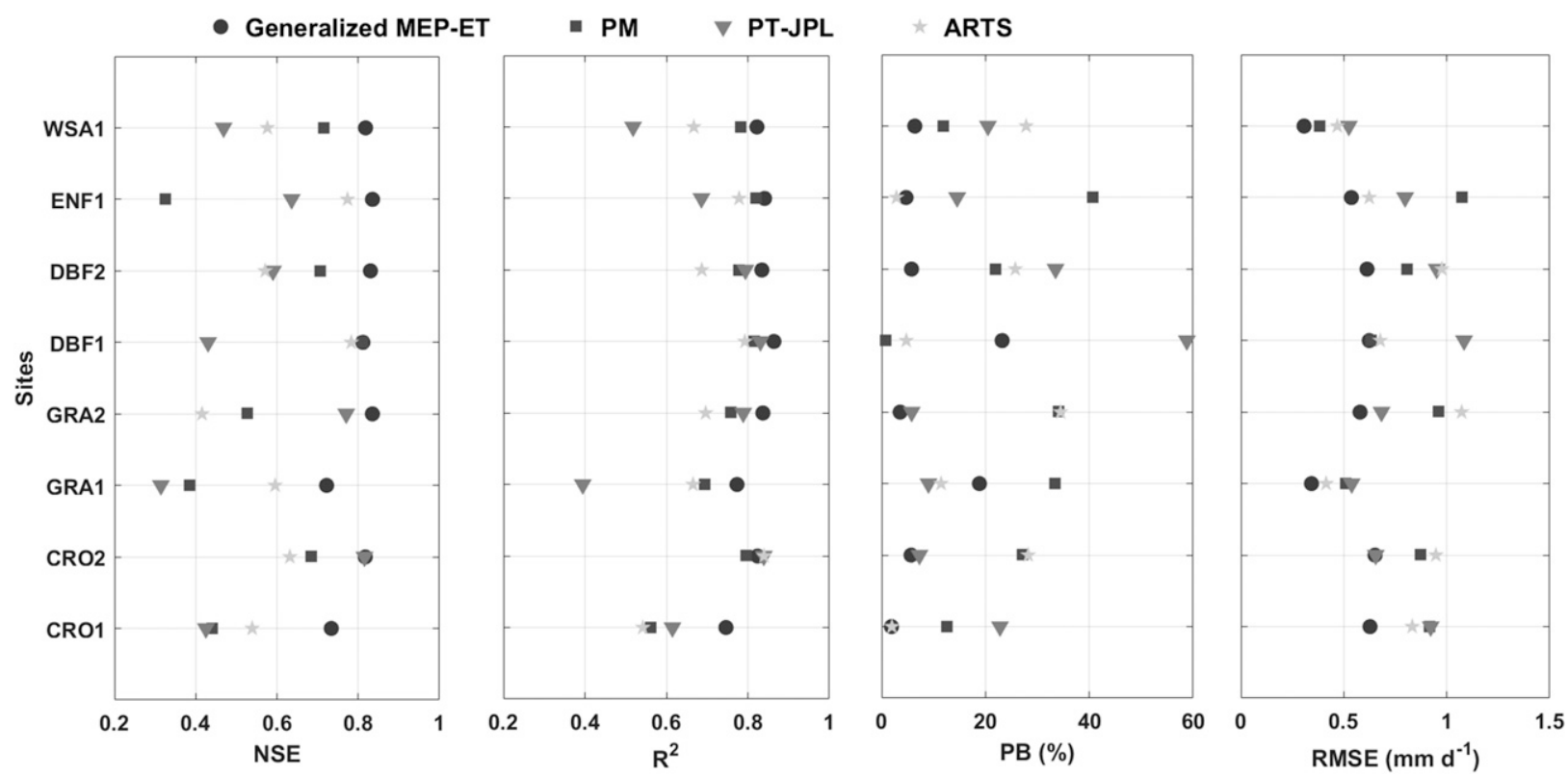

FIG. 9. NSE, $R^{2}$, PB (\%), and RMSE $\left(\mathrm{mm} \mathrm{day}^{-1}\right)$ of the average daily estimated ET over all the years for models across different biome types.

Acknowledgments. The authors would like to acknowledge Anne Morais, who performed some preliminary tests with the MEP model. This work was supported by Ouranos Consortium on Regional Climatology and Adaptation to Climate Change, Hydro-Québec, the Natural Sciences and Engineering Research Council of Canada, the MDDELCC, and Environment and Climate Change Canada through project RDC-477125-14 entitled "Modélisation hydrologique avec bilan énergétique (ÉVAP)." Jingfeng Wang's research is sponsored by NSF CZO Project EAR-1331846 and NASA NEWS Project NNX15AT41G. The authors thank the FLUXNET community, in particular the AmeriFlux community, for allowing the use of their flux data. Finally, we acknowledge fruitful comments and suggestions from the editor and reviewers.

\section{APPENDIX A}

\section{Thermal Inertia Parameters}

As seen in Eq. (1), the entropy production function $D$ is expressed in terms of surface fluxes $(G, H, \mathrm{ET})$ and their associated thermal inertia parameters $I_{s}, I_{a}$, and $I_{e}$. Parameter $I_{s}$ is the thermal inertia parameter of the land surface (i.e., soil or leaf surfaces). For leaf surfaces, this parameter can be neglected since the thermal inertia of the leaf matrix is two orders of magnitude smaller than that of soil. For soil surfaces, $I_{s}$ may be parameterized using an empirical equation according to Wang and Bras (2011):

$$
I_{s}=I_{\mathrm{ds}}+\sqrt{\theta I_{w}}
$$

where $I_{\mathrm{ds}}$ is the thermal inertia of dry soil, $\theta$ is the soil water content, and $I_{w}$ is the thermal inertia of (still) liquid water. The latter can be determined as follows:

$$
I_{w}=\sqrt{\rho_{w} c_{w} k_{w}},
$$

where $\rho_{w}$ is the water density $\left(10^{3} \mathrm{~kg} \mathrm{~m}^{-3}\right), k_{w}$ is heat conductivity $\left(0.58 \mathrm{~W} \mathrm{~m}^{-1} \mathrm{~K}^{-1}\right)$, and $c_{w}$ is the water specific heat $\left(4.18 \times 10^{-3} \mathrm{~J} \mathrm{~kg}^{-1} \mathrm{~K}^{-1}\right)$. In Eq. (A1), $I_{\mathrm{ds}}$ may be estimated following Wang et al. (2010). It is expressed as a proportional coefficient in a linear equation relating the amplitudes of surface soil (ground) heat flux and temperature. In this study, $I_{\mathrm{ds}}$ is calculated at each site following this method under periods that are characterized by strong insolation (high radiation) and in the absence of rain. Parameters $I_{a}$ and $I_{e}$ characterize the turbulent transport of heat and water vapor in the boundary layer, respectively. They are parameterized based on MOST (see Wang and Bras 2010, 2011) as follows:

$$
\begin{aligned}
& I_{a}=I_{0}|H|^{1 / 6} \quad \text { and } \\
& I_{e}=\sigma I_{a},
\end{aligned}
$$

where $\sigma$ is a dimensionless parameter given by Eq. (4). Parameter $I_{0}$ is referred to as apparent thermal inertia of air and is only dependent upon external parameters (Wang and Bras 2009): 


$$
I_{0}=\rho_{a} c_{p} \sqrt{C_{1} \kappa z}\left(C_{2} \frac{k g z}{T_{r} \rho_{a} c_{p}}\right)^{1 / 6},
$$

where $\rho_{a}$ is the air density $\left(\approx 1.22 \mathrm{~kg} \mathrm{~m}^{-3}\right), c_{p}$ is the air specific heat under constant pressure $\left(\approx 1004 \mathrm{~J} \mathrm{~kg}^{-1} \mathrm{~K}^{-1}\right)$, $\kappa$ is the von Kármán constant $(=0.4), z$ is the distance above the surface $(\mathrm{m}), g$ is the gravitational acceleration $\left(\approx 9.81 \mathrm{~m} \mathrm{~s}^{-2}\right), T_{r}$ is a reference temperature $(\approx 300 \mathrm{~K})$, and $C_{1}$ and $C_{2}$ are two empirical constants characterizing the stability of the potential temperature and wind velocity profiles identified by Businger et al. (1971).

\section{APPENDIX B}

\section{Description of the Comparison Models}

\section{a. Modified PM model}

Brutsaert (2005) modified the PM model to calculate actual evapotranspiration by introducing a canopy resistance term to represent the effect of plants on the water vapor transfer through the soil-roots-stemsleaves-air system. The modified PM model was used in this study following Ershadi et al. (2014):

$$
\mathrm{ET}=\frac{1}{\lambda} \frac{\Delta\left(R_{n}-G\right)+\frac{\rho_{a} c_{p}\left(e_{s}-e_{a}\right)}{r_{a}}}{\Delta+\gamma\left(1+\frac{r_{s}}{r_{a}}\right)},
$$

where $\lambda$ is latent heat of vaporization $\left(\mathrm{J} \mathrm{kg}^{-1}\right), \rho_{a}$ is the air density, $c_{p}$ is the specific heat of air, $\Delta$ is the slope of the saturation vapor pressure $\left(\mathrm{Pa} \mathrm{K}^{-1}\right), \gamma$ is the psychrometric constant $\left(\mathrm{Pa} \mathrm{K}^{-1}\right), e_{s}$ is the saturation vapor pressure $(\mathrm{Pa}), e_{a}$ is the actual vapor pressure $(\mathrm{Pa})$, and $r_{a}$ and $r_{s}$ are the aerodynamic and surface resistance $\left(\mathrm{s} \mathrm{m}^{-1}\right)$. The aerodynamic resistance $r_{a}$ was estimated according to Thom (1975):

$$
r_{a}=\frac{1}{\kappa^{2} u_{a}}\left[\ln \left(\frac{z-d_{0}}{z_{0 m}}\right) \ln \left(\frac{z-d_{0}}{z_{0 v}}\right)\right],
$$

where $\kappa$ is the von Kármán constant, $z$ is the reference height above the land surface for measurement of the meteorological variables $(\mathrm{m}), u_{a}$ is wind speed $\left(\mathrm{m} \mathrm{s}^{-1}\right), d_{0}$ is the zero-plane displacement height $(\mathrm{m}), z_{0 \mathrm{~m}}$ is the roughness height for momentum transfer (m), and $z_{0 v}$ is the roughness height for water vapor transfer $(\mathrm{m})$. Parameters $d_{0}, z_{0 m}$, and $z_{0 v}$ are estimated using the following equations:

$$
\begin{aligned}
d_{0} & =0.66 H, \\
z_{0 m} & =0.1 H, \quad \text { and } \\
z_{0 v} & =0.1 z_{0 m},
\end{aligned}
$$

where $H$ is the mean canopy height of the evapotranspiration source $(\mathrm{m})$. For estimation of the surface resistance $r_{s}$, the Jarvis scheme of Jacquemin and Noilhan (1990) is used:

$$
r_{s}=\frac{r_{s}^{\min }}{\mathrm{LAI} \times F_{1} F_{2} F_{3} F_{4}},
$$

where $r_{s}^{\min }$ is the minimum canopy resistance $\left(\mathrm{s} \mathrm{m}^{-1}\right)$. Parameters $F_{1}, F_{2}, F_{3}$, and $F_{4}$ are weighting functions representing the effects of solar radiation, humidity, air temperature, and soil moisture on plant stress:

$$
\begin{aligned}
& F_{1}=\frac{\frac{r_{s}^{\min }}{r_{s}^{\max }}+f}{1+f} \text { with } f=0.55 \frac{R_{g}}{R_{g l}}\left(\frac{2}{\mathrm{LAI}}\right), \\
& F_{2}=\frac{1}{1+h_{s}\left(q^{*}-q\right)}, \\
& F_{3}=1-0.0016\left(T_{\mathrm{ref}}-T_{a}\right)^{2}, \quad \text { and } \\
& F_{4}=\sum_{i=1}^{N_{\mathrm{root}}} \frac{\left(\theta_{i}-\theta_{\text {min }}\right) d_{i}}{\left(\theta_{\text {max }}-\theta_{\text {min }}\right) d_{t}},
\end{aligned}
$$

where $r_{s}^{\max }$ is the maximum or cuticular canopy resistance $\left(\mathrm{s} \mathrm{m}^{-1}\right), R_{g l}$ is the minimum solar radiation necessary for transpiration $\left(\mathrm{W} \mathrm{m}^{-2}\right), R_{g}$ is the incident solar radiation $\left(\mathrm{W} \mathrm{m}^{-2}\right), h_{s}$ is a parameter associated with the water vapor deficit, $q^{*}-q$ represents the water vapor deficit $\left(\mathrm{kg} \mathrm{kg}^{-1}\right), T_{\text {ref }}$ is the optimal temperature for photosynthesis $(\mathrm{K}), T_{a}$ is the air temperature $(\mathrm{K}), d_{i}$ is the thickness of the $i$ th soil layer $(\mathrm{m}), d_{t}$ is the total thickness of the soil layer (m), and $N_{\text {root }}$ is the number of soil layers in the rooting zone. Parameters $\theta_{\max }$ and $\theta_{\min }$ are the soil water contents at field capacity and at the wilting point, respectively.

\section{b. Modified PT-JPL model}

Fisher et al. (2008) modified the PT-JPL model of potential evapotranspiration to estimate actual ET. The modified PT-JPL model consists of three submodels to partition total ET into soil evaporation $E_{s}$, canopy transpiration $E_{c}$, and wet canopy evaporation $E_{\mathrm{wc}}$, that is, $\mathrm{ET}=E_{s}+E_{c}+E_{\mathrm{wc}}$, defined as follows:

$$
\begin{aligned}
E_{c} & =\frac{k_{c}}{\lambda} \alpha_{\mathrm{PT}} \frac{\Delta}{\Delta+\gamma} R_{n}^{c}, \\
E_{s} & =\frac{k_{s}}{\lambda} \alpha_{\mathrm{PT}} \frac{\Delta}{\Delta+\gamma}\left(R_{n}^{s}-G\right), \quad \text { and } \\
E_{\mathrm{wc}} & =\frac{k_{\mathrm{wc}}}{\lambda} \alpha_{\mathrm{PT}} \frac{\Delta}{\Delta+\gamma} R_{n}^{c},
\end{aligned}
$$


where $\alpha_{\mathrm{PT}}$ is the Priestley-Taylor coefficient (=1.26), $R_{n}^{c}$ is the net radiation for the canopy, $R_{n}^{c}=R_{n}-R_{n}^{s} ; R_{n}^{s}$ is the net radiation for soil given by $R_{n}^{s}=R_{n} e^{-0.6 \mathrm{LAI}}$, and $G$ is the ground heat flux $\left(\mathrm{W} \mathrm{m}^{-2}\right)$. Parameters $k_{c}, k_{s}, k_{\mathrm{wc}}$ are the reduction functions for scaling of potential evaporation in each of canopy, soil, and wet canopy components to their actual values and are defined as

$$
\begin{aligned}
k_{c} & =\left(1-f_{\text {wet }}\right) f_{g} f_{T} f_{M}, \\
k_{s} & =f_{\text {wet }}+f_{\text {SM }}\left(1-f_{\text {wet }}\right), \quad \text { and } \\
k_{\text {wc }} & =f_{\text {wet }},
\end{aligned}
$$

where $f_{g}$ is green canopy fraction, $f_{\text {wet }}$ is relative surface wetness, $f_{T}$ is air temperature constraint, and $f_{M}$ and $f_{\mathrm{SM}}$ are empirical factors used as a proxy for plant and soil water stress, respectively:

$$
\begin{aligned}
f_{\mathrm{wet}} & =\mathrm{RH}^{4}, \\
f_{g} & =\frac{f_{\mathrm{APAR}}}{f_{\mathrm{IPAR}}}, \\
f_{T} & =\exp \left[-\left(\frac{T_{a}-T_{\mathrm{opt}}}{T_{\mathrm{opt}}}\right)^{2}\right], \\
f_{M} & =\frac{f_{\mathrm{APAR}}}{f_{\mathrm{APAR}_{\max }}}, \quad \text { and } \\
f_{\mathrm{SM}} & =\mathrm{RH}^{\mathrm{VPD}},
\end{aligned}
$$

where $f_{\mathrm{APAR}}$ and $f_{\mathrm{IPAR}}$ are fractions of the photosynthesis active radiation (PAR) and intercept (IPAR) by green vegetation cover, defined as $f_{\text {APAR }}=1.3632 \times \mathrm{SAVI}-0.048$ and $f_{\mathrm{IPAR}}=\mathrm{NDVI}-0.05$. $\mathrm{RH}$ is the relative humidity (fraction), VPD is vapor pressure deficit $(\mathrm{kPa})$, and the leaf area index is calculated as $\mathrm{LAI}=-\ln \left(1-f_{c}\right) / k_{\mathrm{PAR}}$, with $k_{\mathrm{PAR}}=0.5$ and $f_{c}=f_{\mathrm{IPAR}}$. SAVI is the soil adjusted vegetation index, calculated as SAVI $=0.45 \times \mathrm{NDVI}+0.132$. Finally, the optimum plant growth temperature $T_{\mathrm{opt}}$ is the air temperature defined at the time of maximum activity of the canopy (i.e., when $f_{\mathrm{APAR}}$ and radiation are maximum and VPD is minimum).

\section{c. ARTS model}

Recently, the ARTS model (Yan et al. 2012) has been proposed and tested successfully to estimate ET. Similar to the PT-JPL model, it partitions the total net radiation into soil and vegetation components and calculates potential evaporation from soil and canopy assuming no water stress. Actual ET is obtained by correcting the potential ET according to soil water availability using a soil water balance model. Then, ET is estimated following the five steps described below:

1) Introduce a simple biophysical model for canopy conductance $G_{c}$ :

$$
G_{c}=g_{s_{\max }} f(S) f\left(T_{a}\right) \mathrm{RH} \times \mathrm{LAI},
$$

where $g_{s_{\max }}$ is the maximum stomatal conductance assumed to have a value of $12.2 \mathrm{~mm} \mathrm{~s}^{-1}$. The influence of $S$ and $T_{a}$ follows the definitions of Stewart (1988) and Noilhan and Planton (1989), respectively:

$$
\begin{aligned}
f(S) & =(1+c / 100) \times S /(c+S) \quad \text { and } \\
f\left(T_{a}\right) & =1-0.0016\left(298-T_{a}\right)^{2},
\end{aligned}
$$

where $S$ is solar radiation $\left(\mathrm{W} \mathrm{m}^{-2}\right)$ and $c=100$.

2) Calculate canopy transpiration $E_{c}$ with the $G_{c}$ based in the PM model:

$$
E_{c}=\frac{1}{\lambda} \frac{\Delta R_{n}^{c}+\rho_{a} c_{p}\left(e_{s}-e_{a}\right) G_{a}}{\Delta+\gamma\left(1+\frac{G_{a}}{G_{c}}\right)} .
$$

The aerodynamic conductance $G_{a}$ is calculated using the following equation (Monteith and Unsworth 1990):

$$
G_{a}=\frac{\kappa^{2} u_{a}}{\ln \left(\frac{z-d_{0}}{z_{0 m}}\right) \ln \left(\frac{z-d_{0}}{z_{0 v}}\right)}
$$

3) Calculate soil evaporation $E_{s}$ from an air relativehumidity-based model of evapotranspiration (Yan and Shugart 2010):

$$
E_{s}=\frac{1.35}{\lambda} \mathrm{RH} \frac{\Delta\left(R_{n}^{s}-G\right)}{\Delta+\gamma}
$$

4) Calculate total potential evapotranspiration $\left(\mathrm{ET}_{0}\right)$ as the sum of the canopy transpiration and soil evaporation, assuming the absence of soil water stress:

$$
\mathrm{ET}_{0}=E_{c}+E_{s} .
$$

5) Correct $\mathrm{ET}_{0}$ for soil water stress using the following soil water balance model: 


$$
\begin{aligned}
\frac{d W}{d t} & =P-E T-R_{0}, \\
P & =R_{a}+S_{n} \times S_{f}, \\
S_{f} & = \begin{cases}0, & T_{a} \leq 0^{\circ} \mathrm{C} \\
0.2 T_{a}, & 0^{\circ} \mathrm{C}<T_{a} \leq 5^{\circ} \mathrm{C}, \quad \text { and } \\
1, & T_{a}>5^{\circ} \mathrm{C}\end{cases} \\
\beta & =\frac{\theta_{\text {max }}-\theta_{\text {min }}}{\theta_{\text {min }}} \\
\mathrm{ET} & = \begin{cases}\mathrm{ET}_{0}, & \mathrm{ET}_{0} \leq P \\
P+\beta\left(\mathrm{ET}_{0}-P\right), & \mathrm{ET}_{0}>P\end{cases}
\end{aligned}
$$

where $\theta$ is the soil water content, $d \theta / d t$ is the change of $\theta$ over a time $t, P$ is the water input (mm) including precipitation and snowmelt, $R_{0}$ is runoff $(\mathrm{mm}), R_{a}$ is rainfall $(\mathrm{mm}), S_{n}$ is snowmelt $(\mathrm{mm}), S_{f}$ is the snowmelt factor, $T_{a}$ is air temperature $\left({ }^{\circ} \mathrm{C}\right), \mathrm{ET}_{0}$ is the evapotranspiration for a well-watered surface, already defined in Eq. (B16), $\beta$ is the soil water retention function, defined as the ratio of available soil water content $\left(\theta-\theta_{\min }\right)$ to maximum soil available water content $\left(\theta_{\max }-\theta_{\min }\right), \theta_{\min }$ is the soil water content at wilting point, and $\theta_{\max }$ is the field capacity.

\section{REFERENCES}

Agarwal, D. A., M. Humphrey, N. F. Beekwilder, K. R. Jackson, M. M. Goode, and C. van Ingen, 2010: A data-centered collaboration portal to support global carbon-flux analysis. Concurrency Comput. Pract. Exper., 22, 2323-2334, https:// doi.org/10.1002/cpe.1600.

Aubinet, M., T. Vesala, and D. Papale, 2012: Eddy Covariance: A Practical Guide to Measurement and Data Analysis. Springer, $424 \mathrm{pp}$.

Baldocchi, D. D., B. B. Hincks, and T. P. Meyers, 1988: Measuring biosphere-atmosphere exchanges of biologically related gases with micrometeorological methods. Ecology, 69, 1331-1340, https://doi.org/10.2307/1941631.

_ - E. Falge, L. Gu, and R. Olson, 2001: FLUXNET: A new tool to study the temporal and spatial variability of ecosystemscale carbon dioxide, water vapor, and energy flux densities. Bull. Amer. Meteor. Soc., 82, 2415-2434, https://doi.org/ 10.1175/1520-0477(2001)082<2415:FANTTS > 2.3.CO;2.

Berry, J. A., D. J. Beerling, and P. J. Franks, 2010: Stomata: Key players in the earth system, past and present. Curr. Opin. Plant Biol., 13, 232-239, https://doi.org/10.1016/j.pbi.2010.04.013.

Brutsaert, W., 2005: Hydrology: An Introduction. Cambridge University Press, 618 pp.

Budyko, M. I., 1974: Climate and Life. D. H. Miller, Ed., International Geophysics Series, Vol. 18, Academic Press, 508 pp.

Businger, J. A., J. C. Wyngaard, Y. Izumi, and E. F. Bradley, 1971: Fluxprofile relationships in the atmospheric surface layer. J. Atmos. Sci., 28, 181-189, https://doi.org/10.1175/1520-0469(1971)028<0181: FPRITA $>2.0 . \mathrm{CO} ; 2$.
Calvet, J., J. Noilhan, and P. Bessemoulin, 1998: Retrieving the root-zone soil moisture from surface soil moisture or temperature estimates: A feasibility study based on field measurements. J. Appl. Meteor., 37, 371-386, https://doi.org/ 10.1175/1520-0450(1998)037<0371:RTRZSM>2.0.CO;2.

Duan, Z., and W. Bastiaanssen, 2017: Evaluation of three energy balance-based evaporation models for estimating monthly evaporation for five lakes using derived heat storage changes from a hysteresis model. Environ. Res. Lett., 12, 024005, https:// doi.org/10.1088/1748-9326/aa568e.

Edlefsen, N., and A. Anderson, 1943: Thermodynamics of soil moisture. Hilgardia, 15 (2), 31-298, https://doi.org/10.3733/ hilg.v15n02p031.

Ershadi, A., M. F. McCabe, J. P. Evans, G. Mariethoz, and D. Kavetski, 2013: A Bayesian analysis of sensible heat flux estimation: Quantifying uncertainty in meteorological forcing to improve model prediction. Water Resour. Res., 49, 23432358, https://doi.org/10.1002/wrcr.20231.

—, M. McCabe, J. P. Evans, N. W. Chaney, and E. F. Wood, 2014: Multi-site evaluation of terrestrial evaporation models using FLUXNET data. Agric. For. Meteor., 187, 46-61, https:// doi.org/10.1016/j.agrformet.2013.11.008.

, - — - _ and E. Wood, 2015: Impact of model structure and parameterization on Penman-Monteith type evaporation models. J. Hydrol., 525, 521-535, https://doi.org/10.1016/ j.jhydrol.2015.04.008.

Fisher, J. B., K. P. Tu, and D. D. Baldocchi, 2008: Global estimates of the land-atmosphere water flux based on monthly AVHRR and ISLSCP-II data, validated at 16 FLUXNET sites. Remote Sens. Environ., 112, 901-919, https://doi.org/10.1016/ j.rse.2007.06.025.

Fritschen, L. J., 1966: Evapotranspiration rates of field crops determined by the Bowen ratio method. Agron. J., 58, 339-342, https://doi.org/10.2134/agronj1966.00021962005800030028x.

Gibbs, J. W., 1902: Elementary Principles in Statistical Mechanics. Yale University Press, 207 pp.

Gollan, T., R. Richards, H. Rawson, J. Passioura, D. Johnson, and R. Munns, 1986: Soil water status affects the stomata. Funct. Plant Biol., 13, 459-464, https://doi.org/10.1071/PP9860459.

$\mathrm{Gu}, \mathrm{L}$., and Coauthors, 2006: Direct and indirect effects of atmospheric conditions and soil moisture on surface energy partitioning revealed by a prolonged drought at a temperate forest site. J. Geophys. Res., 111, D16102, https://doi.org/10.1029/ 2006JD007161.

Harbeck, G. E., 1962: A practical field technique for measuring reservoir evaporation utilizing mass-transfer theory. Geological Survey Prof. Paper 272-E, 9 pp., https://pubs.usgs.gov/ pp/0272e/report.pdf.

Hari, P., and L. Kulmala, 2008: Boreal Forest and Climate Change. Springer, $532 \mathrm{pp}$.

Isabelle, P.-E., D. F. Nadeau, A. N. Rousseau, C. Coursolle, and H. A. Margolis, 2015: Applicability of the bulk-transfer approach to estimate evapotranspiration from boreal peatlands. J. Hydrometeor., 16, 1521-1539, https://doi.org/10.1175/ JHM-D-14-0171.1.

Jacquemin, B., and J. Noilhan, 1990: Sensitivity study and validation of a land surface parameterization using the HAPEXMOBILHY data set. Bound.-Layer Meteor., 52, 93-134, https://doi.org/10.1007/BF00123180.

Jaynes, E. T., 1957: Information theory and statistical mechanics. Phys. Rev., 106, 620, https://doi.org/10.1103/PhysRev.106.620. 2003: Probability Theory: The Logic of Science. Cambridge University Press, $650 \mathrm{pp}$. 
Ji, S., and Coauthors, 2017: A modified optimal stomatal conductance model under water-stressed condition. Int. J. Plant Prod., 11, 295-314.

Kleidon, A., 2009: Nonequilibrium thermodynamics and maximum entropy production in the Earth system. Naturwissenschaften, 96, 1-25, https://doi.org/10.1007/s00114-009-0509-x.

— and the Production of Entropy: Life, Earth, and Beyond. Springer, $264 \mathrm{pp}$.

Kohler, M. A., T. J. Nordenson, and W. Fox, 1955: Evaporation from pans and lakes. NOAA Weather Bureau Research Paper 38, $21 \mathrm{pp}$.

Kustas, W., and J. Norman, 1996: Use of remote sensing for evapotranspiration monitoring over land surfaces. Hydrol. Sci. J., 41, 495-516, https://doi.org/10.1080/02626669609491522.

Martyushev, L., and V. Seleznev, 2006: Maximum entropy production principle in physics, chemistry and biology. Phys. Rep., 426, 1-45, https://doi.org/10.1016/j.physrep.2005.12.001.

Massman, W., and X. Lee, 2002: Eddy covariance flux corrections and uncertainties in long-term studies of carbon and energy exchanges. Agric. For. Meteor., 113, 121-144, https://doi.org/ 10.1016/S0168-1923(02)00105-3.

Misson, L., J. A. Panek, and A. H. Goldstein, 2004: A comparison of three approaches to modeling leaf gas exchange in annually drought-stressed ponderosa pine forests. Tree Physiol., 24, 529-541, https://doi.org/10.1093/treephys/24.5.529.

Monteith, J., and M. Unsworth, 1990: The radiation environment. Principles of Environmental Physics, 2nd ed., Edward Arnold, 36-57.

Müller, J., A. Eschenröder, and O. Christen, 2014: LEAFC3-N photosynthesis, stomatal conductance, transpiration and energy balance model: Finite mesophyll conductance, drought stress, stomata ratio, optimized solution algorithms, and code. Ecol. Modell., 290, 134-145, https://doi.org/10.1016/ j.ecolmodel.2013.10.036.

Noilhan, J., and S. Planton, 1989: A simple parameterization of land surface processes for meteorological models. Mon. Wea. Rev., 117, 536-549, https://doi.org/10.1175/ 1520-0493(1989)117<0536:ASPOLS>2.0.CO;2.

Ozawa, H., A. Ohmura, R. D. Lorenz, and T. Pujol, 2003: The second law of thermodynamics and the global climate system: A review of the maximum entropy production principle. Rev. Geophys., 41, 1018, https://doi.org/10.1029/2002RG000113.

Penman, H. L., 1948: Natural evaporation from open water, bare soil and grass. Proc. Roy. Soc. London, 193A, 120-145, https:// doi.org/10.1098/rspa.1948.0037.

Pereira, L. S., P. Paredes, G. C. Rodrigues, and M. Neves, 2015: Modeling malt barley water use and evapotranspiration partitioning in two contrasting rainfall years. Assessing AquaCrop and SIMDualKc models. Agric. Water Manage., 159, 239-254, https://doi.org/10.1016/j.agwat.2015.06.006.

Pontailler, J.-Y., G. J. Hymus, and B. G. Drake, 2003: Estimation of leaf area index using ground-based remote sensed NDVI measurements: Validation and comparison with two indirect techniques. Can. J. Remote Sens., 29, 381-387, https://doi.org/ 10.5589/m03-009.

Priestley, C. H. B., and R. J. Taylor, 1972: On the assessment of surface heat flux and evaporation using large scale parameters. Mon. Wea. Rev., 100, 81-92, https://doi.org/10.1175/1520-0493 (1972) $100<0081$ :OTAOSH $>2.3$.CO;2.

Qi, J., and Coauthors, 2000: Spatial and temporal dynamics of vegetation in the San Pedro River basin area. Agric. For. Meteor., 105, 55-68, https://doi.org/10.1016/S0168-1923(00)00195-7.
Sala, A., and J. Tenhunen, 1996: Simulations of canopy net photosynthesis and transpiration in Quercus ilex L. under the influence of seasonal drought. Agric. For. Meteor., 78, 203-222, https://doi.org/10.1016/0168-1923(95)02250-3.

Shanafield, M., P. G. Cook, H. A. Gutiérrez-Jurado, R. Faux, J. Cleverly, and D. Eamus, 2015: Field comparison of methods for estimating groundwater discharge by evaporation and evapotranspiration in an arid-zone playa. J. Hydrol., 527, 1073-1083, https://doi.org/10.1016/j.jhydrol.2015.06.003.

Shannon, C. E., 1948: A mathematical theory of communication. Bell Syst. Tech. J., 27, 379-423, https://doi.org/10.1002/ j.1538-7305.1948.tb01338.x.

Shi, T., D. Guan, A. Wang, J. Wu, C. Jin, and S. Han, 2008: Comparison of three models to estimate evapotranspiration for a temperate mixed forest. Hydrol. Processes, 22, 34313443, https://doi.org/10.1002/hyp.6922.

Spanner, M. A., L. L. Pierce, S. W. Running, and D. L. Peterson, 1990: The seasonality of AVHRR data of temperate coniferous forests: Relationship with leaf area index. Remote Sens. Environ., 33, 97-112, https://doi.org/10.1016/0034-4257 (90)90036-L.

Stewart, J., 1988: Modelling surface conductance of pine forest. Agric. For. Meteor., 43, 19-35, https://doi.org/10.1016/0168-1923 (88) $90003-2$

Thom, A. S., 1975: Momentum, mass, and heat exchange of plant communities. Vegetation and the Atmosphere, J. L. Monteith, Ed., Academic Press, 57-109.

Tuzet, A., A. Perrier, and R. Leuning, 2003: A coupled model of stomatal conductance, photosynthesis and transpiration. Plant Cell Environ., 26, 1097-1116, https://doi.org/10.1046/j.1365-3040.2003.01035.x.

Uddling, J., M. Hall, G. Wallin, and P. E. Karlsson, 2005: Measuring and modelling stomatal conductance and photosynthesis in mature birch in Sweden. Agric. For. Meteor., 132, 115-131, https://doi.org/10.1016/j.agrformet.2005.07.004.

Van Wijk, M., S. Dekker, W. Bouten, F. Bosveld, W. Kohsiek, K. Kramer, and G. Mohren, 2000: Modeling daily gas exchange of a Douglas-fir forest: Comparison of three stomatal conductance models with and without a soil water stress function. Tree Physiol., 20, 115-122, https://doi.org/10.1093/ treephys/20.2.115.

Wang, H., D. Tetzlaff, and C. Soulsby, 2017: Testing the maximum entropy production approach for estimating evapotranspiration from closed canopy shrub land in a low-energy humid environment. Hydrol. Processes, 31, 4613-4621, https://doi.org/ 10.1002/hyp.11363.

Wang, J., and R. L. Bras, 2009: A model of surface heat fluxes based on the theory of maximum entropy production. Water Resour. Res., 45, W11422, https://doi.org/10.1029/2009WR007900.

_, and - 2010: An extremum solution of the MoninObukhov similarity equations. J. Atmos. Sci., 67, 485-499, https://doi.org/10.1175/2009JAS3117.1.

— and - 2011: A model of evapotranspiration based on the theory of maximum entropy production. Water Resour. Res., 47, W03521, https://doi.org/10.1029/2010WR009392.

,,-- G. Sivandran, and R. Knox, 2010: A simple method for the estimation of thermal inertia. Geophys. Res. Lett., 37, L05404, https://doi.org/10.1029/2009GL041851.

— — _ - P. Goyal, A. Giffin, K. H. Knuth, and E. Vrscay, 2012: An application of the maximum entropy production principle in modeling heat fluxes over land surfaces. AIP Conf. Proc., 1443, 282-289, https://doi.org/10.1063/1.3703645.

, V. Nieves, and R. L. Bras, 2013: MaxEnt and MaxEP in modeling fractal topography and atmospheric turbulence. 
Beyond the Second Law: Entropy Production and NonEquilibrium Systems, R. Dewar et al., Eds., Springer, 309322, https://doi.org/10.1007/978-3-642-40154-1_16.

Wang, Y.-P., and R. Leuning, 1998: A two-leaf model for canopy conductance, photosynthesis and partitioning of available energy I: Model description and comparison with a multilayered model. Agric. For. Meteor., 91, 89-111, https://doi.org/ 10.1016/S0168-1923(98)00061-6.

Williams, C. A., and Coauthors, 2012: Climate and vegetation controls on the surface water balance: Synthesis of evapotranspiration measured across a global network of flux towers. Water Resour. Res., 48, W06523, https://doi.org/10.1029/ 2011WR011586.

Williams, M., and Coauthors, 2009: Improving land surface models with FLUXNET data. Biogeosciences, 6, 1341-1359, https:/ doi.org/10.5194/bg-6-1341-2009.

Wilson, K., and Coauthors, 2002: Energy balance closure at FLUXNET sites. Agric. For. Meteor., 113, 223-243, https:// doi.org/10.1016/S0168-1923(02)00109-0.
Wittich, K., and O. Hansing, 1995: Area-averaged vegetative cover fraction estimated from satellite data. Int. J. Biometeor., 38, 209-215, https://doi.org/10.1007/BF01245391.

Yan, H., and H. H. Shugart, 2010: An air relative-humidity based evapotranspiration model from eddy covariance data. J. Geophys. Res., 115, D16106, https://doi.org/10.1029/2009JD013598.

— tion using a leaf area index-based surface energy and water balance model. Remote Sens. Environ., 124, 581-595, https:// doi.org/10.1016/j.rse.2012.06.004.

Zhao, L., J. Xia, C.-y. Xu, Z. Wang, L. Sobkowiak, and C. Long, 2013: Evapotranspiration estimation methods in hydrological models. J. Geogr. Sci., 23, 359-369, https://doi.org/10.1007/ s11442-013-1015-9.

Zotarelli, L., M. Dukes, and K. Morgan, 2010: Interpretation of soil moisture content to determine soil field capacity and avoid overirrigating sandy soils using soil moisture sensors. IFAS Publ. AE460, University of Florida, 4 pp., http://edis.ifas.ufl.edu/ ae460. 